\title{
Synchronous Triple Gastric Cancer Incorporating Mixed Adenocarcinoma and Neuroendocrine Tumor Completely Resected with Endoscopic Submucosal Dissection
}

\author{
Kimitoshi Kubo ${ }^{1}$, Noriko Kimura ${ }^{2}$, Katsuhiro Mabe ${ }^{1}$, \\ Yusuke Nishimura ${ }^{1}$ and Mototsugu Kato ${ }^{1}$
}

\begin{abstract}
:
The endoscopic and pathological features of early gastric mixed adenoneuroendocrine carcinoma (MANEC), as well as its carcinogenesis, remain largely unclear. Screening esophagogastroduodenoscopy was performed on an 80-year-old man, revealing 3 superficial elevated lesions. Endoscopic submucosal dissection (ESD) was performed, and the patient was diagnosed with intramucosal gastric cancer comprising mixed adenocarcinoma and neuroendocrine tumor, well-differentiated adenocarcinoma and well-differentiated adenocarcinoma, with negative margins. To our knowledge, this is the first report describing the endoscopic and pathological findings of synchronous triple gastric cancer incorporating mixed adenocarcinoma and neuroendocrine tumor completely resected with ESD.
\end{abstract}

Key words: gastric MANEC, gastric triple carcinoma, endoscopic treatment

(Intern Med 57: 2951-2955, 2018)

(DOI: 10.2169/internalmedicine.0842-18)

\section{Introduction}

Mixed adenoneuroendocrine carcinoma (MANEC) (1) is a tumor composed of both adenocarcinoma and neuroendocrine carcinoma (NEC) components, with each comprising at least $30 \%$ of the lesion. La Rosa et al. (2) classified MANECs into high-grade tumors composed of adenocarcinoma and NEC and intermediate-grade tumors composed of mixed adenocarcinoma and G1/G2 neuroendocrine tumor (NET). The endoscopic and pathological features of early gastric MANEC remain poorly described.

We herein report a case of synchronous triple gastric cancer incorporating MANEC completely resected with endoscopic submucosal dissection (ESD).

\section{Case Report}

Screening esophagogastroduodenoscopy (EGD) was performed on an 80-year-old man, revealing 3 superficial ele- vated lesions in the anterior wall of the middle gastric body, the posterior wall of the gastric angle, and the lesser gastric body (Fig. 1). The patient was shown to be positive for serum IgG antibody to Helicobacter pylori but negative for anti-parietal cells and anti-intrinsic factor antibodies, suggesting the presence of $H$. pylori-associated atrophic gastritis.

ESD was performed on suspected well-differentiated tubular adenocarcinoma (Fig. 2). Histologically, the tumor in the anterior wall showed two distinct components of tubular adenocarcinoma: well-differentiated type (tub1) and NET G1, which represented the major and minor components, respectively, each accounting for $>30 \%$ of the tumor (Fig. 3). The NET component, which was positive for chromogranin A (Fig. 4A), synaptophysin and serotonin (Fig. 4B), was shown to have infiltrated into the muscularis mucosae (Fig. 5). The tumor was diagnosed as mixed adenocarcinoma and neuroendocrine tumor, G1.

The patient was thus eventually diagnosed with intramucosal gastric cancer comprising: 1) 0 -IIa $25 \times 22 \mathrm{~mm}$ mixed

${ }^{1}$ Department of Gastroenterology, National Hospital Organization Hakodate Hospital, Japan and ${ }^{2}$ Department of Pathology, National Hospital Organization Hakodate Hospital, Japan

Received: January 17, 2018; Accepted: March 11, 2018; Advance Publication by J-STAGE: May 18, 2018

Correspondence to Dr. Kimitoshi Kubo, kubotti25@yahoo.co.jp 


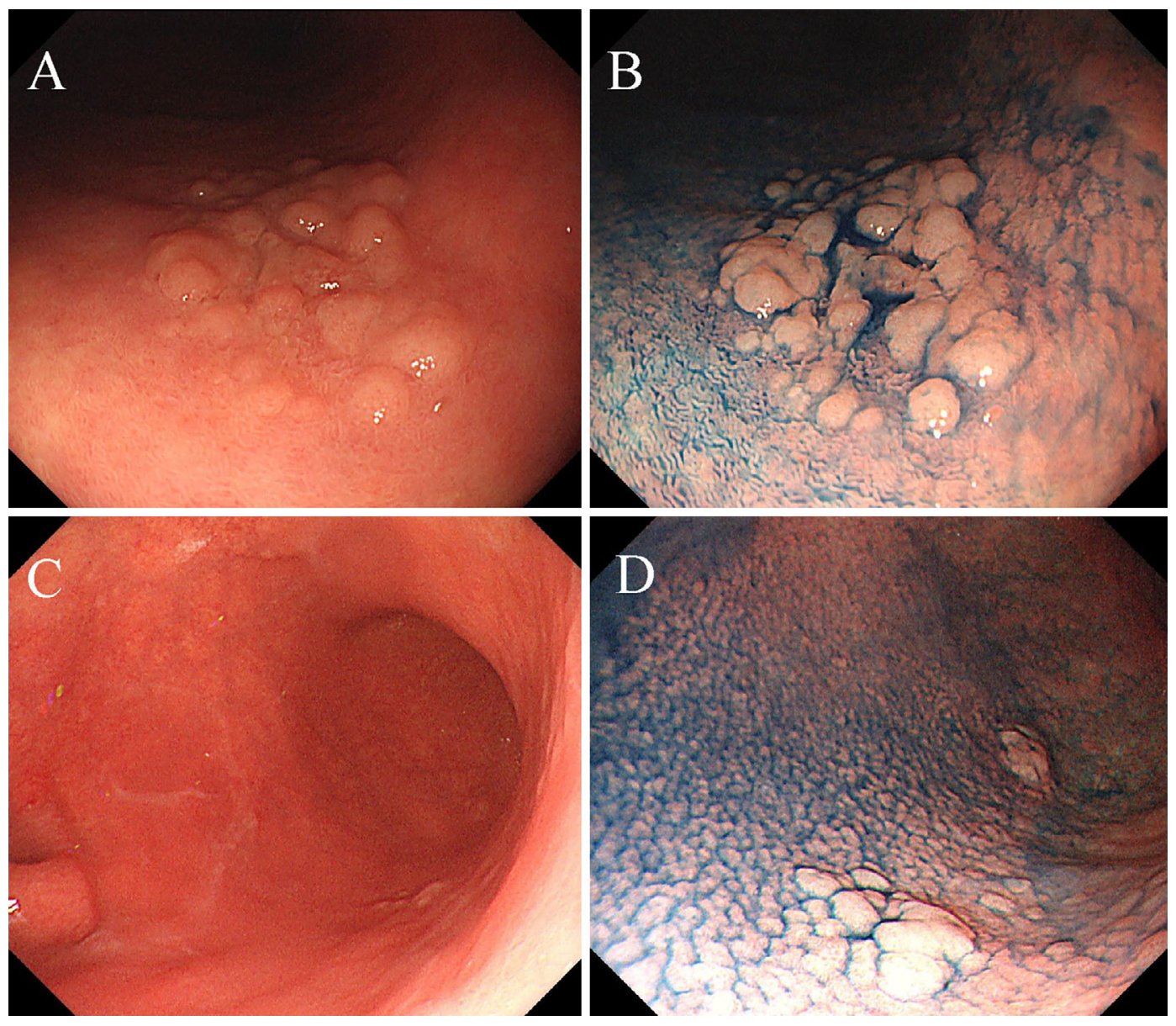

Figure 1. Esophagogastroduodenoscopy. (A) A superficial elevated lesion in the anterior wall of the middle gastric body; (B) chromoendoscopy with indigo carmine showing the border of the lesion; (C) superficial elevated lesions in the posterior wall of the gastric angle and the lesser gastric body and (D) chromoendoscopy with indigo carmine showing the border of the lesions.

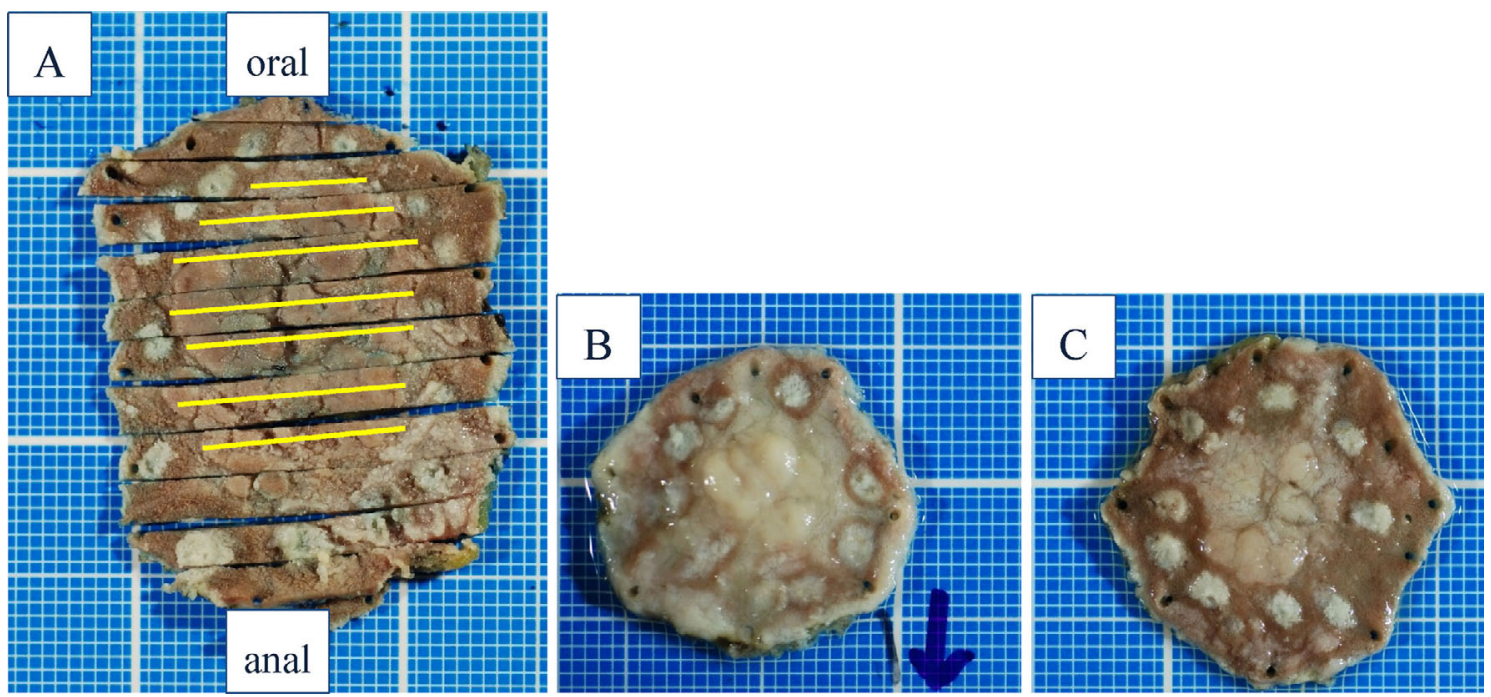

Figure 2. A macroscopic view of the resected specimen. (A) The lesion in the anterior wall of the middle gastric body was 0 -IIa $25 \times 22 \mathrm{~mm}$, (B) the lesion in the posterior wall of the gastric angle was 0 -IIa $11 \times 9 \mathrm{~mm}$, and (C) the lesion in the posterior wall of the lesser gastric body was 0-IIa $12 \times 12 \mathrm{~mm}$.

adenocarcinoma, tub1 and NET, G1; 2) 0-IIa $11 \times 9 \mathrm{~mm}$ adenocarcinoma, tub1; and 3) 0-IIa $12 \times 12 \mathrm{~mm}$ adenocarcinoma, tub1. Each of these sections was shown to have negative margins. H. pylori was successfully eradicated after ESD. 


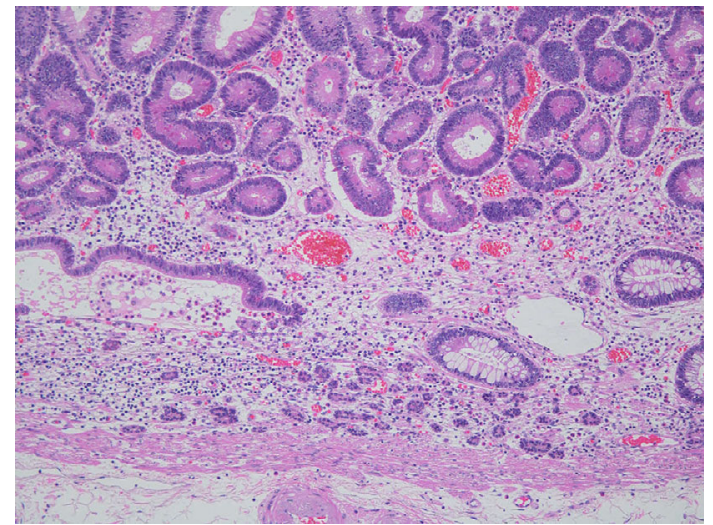

Figure 3. A histopathologic examination of the lesion in the anterior wall. The tumor was composed of tubular adenocarcinoma (tub1) and neuroendocrine tumor (NET, G1). Both tumors were similarly composed of small tubular structures, but the tumor cells of the NET were characterized by smaller tubules with eosinophilic granular cytoplasm distributed in the lower mucosal layer (Hematoxylin and Eosin staining).
EGD and computed tomography examinations six month later revealed no recurrence or metastasis.

\section{Discussion}

Two important clinical issues emerged in our case. First, gastric MANEC may present as an intramucosal lesion. According to recent reports, gastric MANEC presents as an advanced tumor in most cases and is associated with a poor prognosis even when surgically treated (3). In 1987, Lewin (4) proposed the classification of gastrointestinal tumors with exocrine and neuroendocrine components as follows: 1) collision tumors, 2) combined tumors and 3) amphicrine tumors.

Under the 2010 WHO classification, MANEC (1) is a tumor composed of both adenocarcinoma and NEC components, with each comprising at least $30 \%$ of the lesion. La Rosa et al. (2) classified MANECs as high-grade tumors composed of adenocarcinoma and NEC and intermediategrade tumors composed of mixed adenocarcinoma and G1/G2 NET, according to the grade of malignancy of each
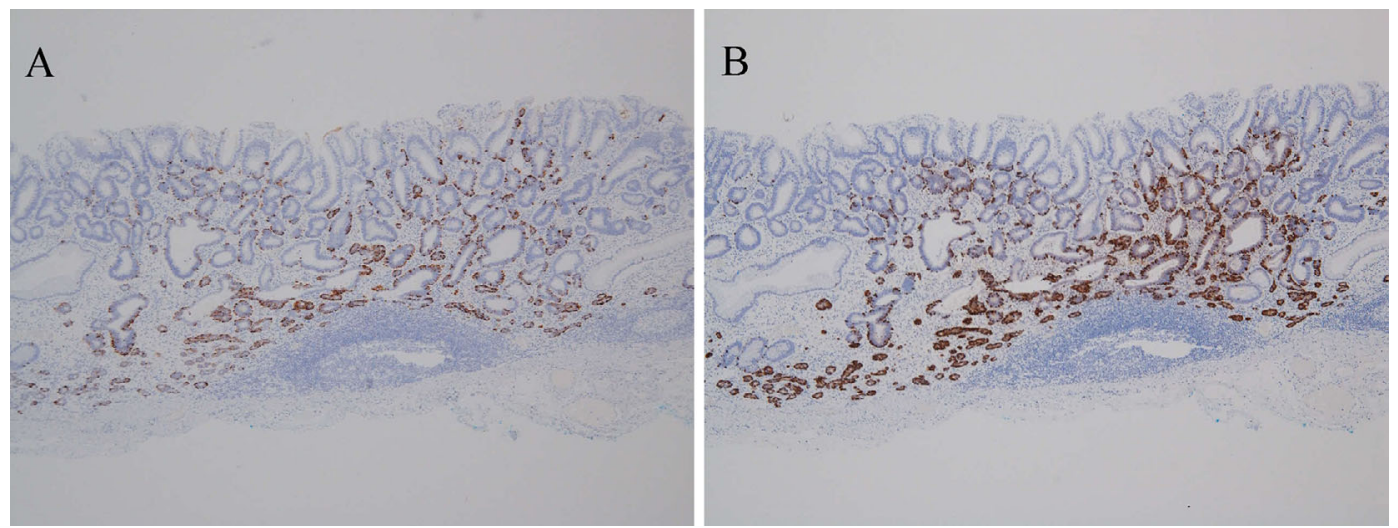

Figure 4. Immunohistological staining of the lesion in the anterior wall. (A) The NET component was positive for chromogranin A (A) and serotonin (B).
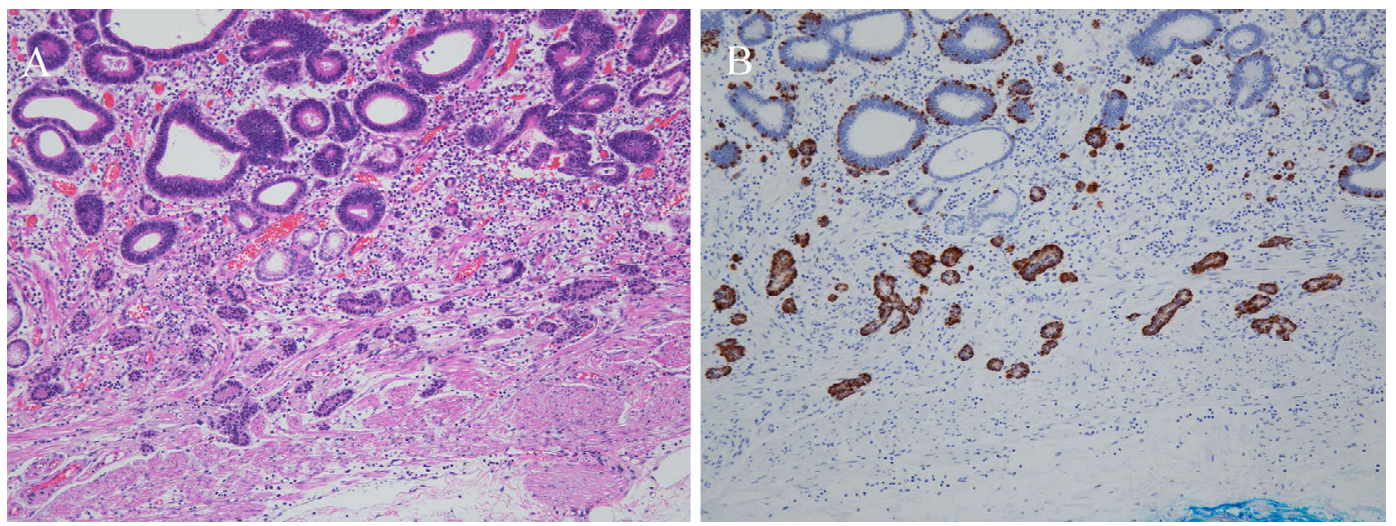

Figure 5. A histopathologic examination and immunohistological staining of the lesion in the anterior wall. (A) The tumor cells of the NET component were shown to have infiltrated into the muscularis mucosa (Hematoxylin and Eosin staining). (B) Tumor cells positive for serotonin in the NET component were shown to have infiltrated into the muscularis mucosa and to have merged with some of the adenocarcinoma component. 
Table. Cases Reported to Date of Gastric MANEC Resected with ESD.

\begin{tabular}{|c|c|c|c|c|c|c|c|c|c|c|c|}
\hline No & Reference & Year & Age & Sex & Location & Type & $\begin{array}{l}\text { Size } \\
(\mathrm{mm})\end{array}$ & Component & Depth & Treatment & Clinical course \\
\hline 1 & [5] & 2013 & 70 & $\mathrm{~F}$ & $\begin{array}{l}\text { Greater curvature } \\
\text { of the antrum }\end{array}$ & 0-IIc & $14 \times 13$ & $\begin{array}{c}\text { Adenocarcinoma and } \\
\text { NEC }\end{array}$ & SM & ESD & $\begin{array}{l}\text { No recurrence } \\
\text { for } 12 \text { months }\end{array}$ \\
\hline 2 & [6] & 2014 & 80 & M & $\begin{array}{l}\text { Lesser curvature } \\
\text { of the upper } \\
\text { gastric body }\end{array}$ & 0-IIa & $10 \times 9$ & $\begin{array}{c}\text { Adenocarcinoma and } \\
\text { NEC }\end{array}$ & SM & $\begin{array}{c}\text { ESD, } \\
\text { Gastrectomy }\end{array}$ & $\begin{array}{c}\text { No recurrence } \\
\text { for } 3 \text { years }\end{array}$ \\
\hline 3 & [7] & 2014 & 77 & M & $\begin{array}{l}\text { Lesser curvature } \\
\text { of the antrum }\end{array}$ & 0-IIc & $10 \times 6$ & $\begin{array}{c}\text { Adenocarcinoma and } \\
\text { NEC }\end{array}$ & M & ESD & $\begin{array}{l}\text { No recurrence } \\
\text { for } 7 \text { months }\end{array}$ \\
\hline 4 & Our case & 2018 & 80 & $\mathrm{M}$ & $\begin{array}{l}\text { Anterior wall of } \\
\text { the middle } \\
\text { gastric body }\end{array}$ & 0-IIa & $25 \times 22$ & $\begin{array}{c}\text { Adenocarcinoma and } \\
\text { NET G1 }\end{array}$ & M & ESD & $\begin{array}{l}\text { No recurrence } \\
\text { for } 6 \text { months }\end{array}$ \\
\hline
\end{tabular}

MANEC: mixed adenoneuroendocrine carcinoma, ESD: endoscopic submucosal dissection, NEC: neuroendocrine carcinoma, NET: neuroendocrine tumor

component. The present lesion was mixed adenocarcinoma and NET G1, which was compatible with intermediate-grade MANEC. To date, three cases of ESD-resected gastric highgrade MANEC have been reported (5-7) (Table). However, of these, only one was classified as an intramucosal lesion in terms of the histological depth, with the other two classified as submucosal lesions. Therefore, the endoscopic and pathological features of early gastric MANEC remain poorly described. Furthermore, the carcinogenesis of MANEC remains unclear. At least two possible hypotheses have been proposed: 1) the partial differentiation of adenocarcinoma into neuroendocrine cells (8) and 2) the bidirectional transformation of monoclonal pluripotent epithelial stem cells into adenocarcinoma and neuroendocrine cells (9). In the present case, the components of adenocarcinoma and NET showed a clear tissue distribution but merged into each other at the border. A case of mixed adenocarcinoma and NET G1 of the rectum was recently reported to have likely differentiated from common putative precursor cells bi-directionally at an early stage of tumorigenesis, given the absence of any NET component in the surface epithelium as well as the evidence of monoclonal pluripotent epithelial stem cells (10). In our case, no NET component was observed at the surface epithelium either, suggesting that gastric mixed adenocarcinoma (tub1) and NET (G1) might have differentiated from monoclonal pluripotent epithelial stem cells. To our knowledge, this is the first report describing the endoscopic and pathological findings of gastric mixed adenocarcinoma and NET G1 completely resected with ESD.

The second important clinical issue that emerged in our case is that gastric mixed adenocarcinoma and neuroendocrine tumor may be derived from $H$. pylori-associated chronic gastritis as well as from gastric cancer. Gastric NETs are categorized into three types: type I, which is associated with autoimmune chronic atrophic gastritis; type II, which is associated with multiple endocrine neoplasia type 1 (MEN 1) and Zollinger-Ellison syndrome; and type III, which is shown to occur sporadically (11). Recently, type I gastric NET was reported to be associated with excessive gastrin secretion secondary to atrophic gastritis and might be derived from $H$. pylori-associated chronic gastritis (12). Re- ports of type I gastric NET with hypergastrinemia following H. pylori-associated chronic gastritis have also been published $(13,14)$. In our case, the patient was shown to be positive for serum IgG antibody to $H$. pylori but negative for anti-parietal cells and anti-intrinsic factor antibodies, and blood tests 2 months after the withdrawal of vonoprazan revealed hypergastrinemia (gastrin, up to $1,360 \mathrm{pg} / \mathrm{mL}$ ).

In addition, given that endocrine cell hyperplasia and endocrine cell micronests were not recognized in the background gastric mucosa, hypergastrinemia following $H$. pylori-associated atrophic gastritis was thought likely to be responsible for the condition. We therefore concluded that synchronous triple gastric cancer incorporating gastric mixed adenocarcinoma and neuroendocrine tumor all developed against a background of $\mathrm{H}$. pylori-associated chronic gastritis. To our knowledge, this is the first report describing gastric mixed adenocarcinoma and type I NET G1 probably derived from $H$. pylori-associated chronic gastritis.

In conclusion, gastric mixed adenocarcinoma and NET G1 may present as an intramucosal lesion and be derived from H. pylori-associated chronic gastritis as well as from gastric cancer. Further studies are needed in order to determine whether or not gastric mixed adenocarcinoma and NET G1 may arise from $\mathrm{H}$. pylori-associated chronic gastritis.

\section{The authors state that they have no Conflict of Interest (COI).}

\section{References}

1. Bosman F, Carneiro F, Hruban R, et al. WHO classification of tumours of the digestive system. 4th ed. IARC, Lyon, 2010: 64-68.

2. La Rosa S, Marando A, Sessa F, et al. Mixed adenoneuroendocrine carcinomas (MANECs) of the gastrointestinal tract: an update. Cancers 4: 11-30, 2012.

3. Shen $\mathrm{C}$, Chen $\mathrm{H}$, Chen $\mathrm{H}$, et al. Surgical treatment and prognosis of gastric neuroendocrine neoplasms: a single-center experience. BMC Gastroenterol 16: 111, 2016.

4. Lewin K. Carcinoid tumors and the mixed (composite) glandularendocrine cell carcinomas. Am J Surg Pathol 11: S71-S86, 1987.

5. Lee JH, Kim HW, Kang DH, et al. A gastric composite tumor with an adenocarcinoma and a neuroendocrine carcinoma: a case 
report. Clin Endosc 46: 280-283, 2013.

6. Fukuba N, Yuki T, Ishihara S, et al. Gastric mixed adenoneuroendocrine carcinoma with a good prognosis. Intern Med 53: 2585 2588, 2014.

7. Yamasaki Y, Nasu J, Miura K, et al. Intramucosal gastric mixed adenoneuroendocrine carcinoma completely resected with endoscopic submucosal dissection. Intern Med 54: 917-920, 2015.

8. Domori K, Nishikura K, Ajioka K, et al. Mucin phenotype expression of gastric neuroendocrine neoplasms: analysis of histopathology and carcinogenesis. Gastric Cancer 17: 263-272, 2014.

9. Furlan D, Cerutti R, Genasetti A, et al. Microallelotyping defines the monoclonal or the polyclonal origin of mixed and collision endocrine-exocrine tumors of the gut. Lab Invest 83: 963-971, 2003.

10. Kanno-Okada K, Mitsuhashi T, Mabe K, et al. Composite neuroendocrine tumor and adenocarcinoma of the rectum. Diagn Pathol 12: 85, 2017.

11. Delle Fave G, Kwekkeboom DJ, Van Cutsem E, et al. ENETS consensus guidelines for the management of patients with gastroduodenal neoplasms. Neuroendocrinology 95: 74-87, 2012.

12. Kaltsas G, Grozinsky-Glasberg S, Alexandraki KI, et al. Current concepts in the diagnosis and management of type I gastric neuroendocrine neoplasms. Clin Endocrinol 81: 157-168, 2014.

13. Sato $Y$, Imamura $H$, Kaizaki $Y$, et al. Management and clinical outcomes of type I gastric carcinoid patients: Retrospective, multicenter study in Japan. Dig Endosc 26: 377-384, 2014.

14. Yamaguchi E, Iwasa $T$, Ihara $E$, et al. Gastric neuroendocrine tumor with hypergastrinemia following type B chronicatrophic gastritis: a case report. Nihon Shokakibyo Gakkai Zasshi 114: 248255, 2017 (in Japanese, Abstract in English).

The Internal Medicine is an Open Access journal distributed under the Creative Commons Attribution-NonCommercial-NoDerivatives 4.0 International License. To view the details of this license, please visit (https://creativecommons.org/licenses/ by-nc-nd/4.0/).

(C) 2018 The Japanese Society of Internal Medicine

Intern Med 57: 2951-2955, 2018 